\title{
Mães e madrastas: mitos sociais e autoconceito $^{1}$
}

\author{
Denise Falcke \\ Adriana Wagner
}

Pontifícia Universidade Católica do Rio Grande do Sul

Resumo

Esta é uma pesquisa sobre os mitos sociais relativos aos papéis femininos de mãe e madrasta e o autoconceito de mulheres que desempenham esses papéis. Participaram desta pesquisa 50 mães e 50 madrastas residentes na cidade de Porto Alegre (RS). O instrumento foi composto de 3 partes: dados de identificação, a escala de mitos sociais e a escala de autoconceito de Butler e Haigh. A análise estatística dos dados demonstrou que tanto mães como madrastas ainda têm a visão histórica da mulher como responsável pelo bem-estar da família. Sendo assim, é esperado, tanto de mães como de madrastas, que exerçam as funções de cuidadora, educadora e suporte afetivo. Apesar deste aspecto ser semelhante para mães e madrastas, na comparação com os itens da escala de autoconceito, verificou-se que as mães consideram-se mais equilibradas apesar de também perceberem-se mais escravizadas, confiando menos em suas próprias emoções e tentando não pensar nos seus problemas. Já as madrastas demonstram estar mais desesperadas, considerando-se fracassadas e tendo uma forte tendência a verem suas vidas mais confusas. Além disso, considerando somente o grupo de madrastas, foi possível constatar que aquelas que possuem filhos apresentam um maior índice de depressão e as madrastas que possuem companheiros viúvos possuem um maior autoconceito social.

Palavras-chave:

Mãe, Madrasta, Mitos sociais, Autoconceito 
Key words:

Mother,

Stepmother, Social myths, Self-concept

\section{Abstract}

Mothers and stepmothers: Social myths and self-concept

This is a research about the social myths related to feminine roles of a mother and stepmother and the self-concept of these women. The sample was 50 mothers and 50 stepmothers who lived in Porto Alegre/RS. The instrument was composed of three (3) parts: information data, the social myth's scale and the self-concept scale of Butler and Haigh. The statistical data analysis showed that mothers as well as stepmothers still have the historical view that mother is the responsible for the well-being of the family. Therefore, it is still expected from mothers as well as from stepmothers, that they should carry out their functions as a caretaker, teacher and affective support. Besides this aspect being similar to mothers and stepmothers, in the comparison with the items of the selfconcept scale, it showed, that the mothers consider themselves more balanced inspite considering themselves also more as a slave, trusting their own emotions less and trying not to think of their problems, meanwhile the stepmothers prove to be more desperate, considering themselves more unsuccessful and having a strong tendency to consider their lives more confused. Besides, considering only the step-mother group, it was possible to see, that the stepmothers, who have children, present a higher index of depression and that the stepmothers, who have a widower as a companion, have a higher social selfconcept.

\footnotetext{
A complexidade que envolve a figura da madrasta encontra-se refletida desde a literatura infantil até as pesquisas mais reRentes sobre o papel da mulher e da mãe no cotidiano social.
Refletindo sobre estas questões, pode-se fazer um neologismo com a grafia da palavra e perguntar-se: por que "má-drasta" e não "boadrasta", ou ainda, "mãe-drasta"?
} 
À mãe, geralmente, atribui-se a idéia mítica de ideal de amor e afeição. Apesar do crescente questionamento sobre o amor materno incondicional e inato, a visão da mãe ideal, responsável pelo bemestar psicológico e emocional da família (McGoldrick \& Carter, 1995; Smith, 1995; Teyber, 1995), ainda é bastante presente na literatura e no senso comum (Badinter, 1985).

Por outro lado, Cinderela e Branca de Neve nos ensinam, há muito tempo, que as madrastas são egoístas, frias e cruéis (Teyber, 1995). Sentimentos de pouco amor-próprio, ansiedade, hostilidade, culpa e melancolia são comumente relacionados à imagem desta personagem (Bassoff, 1990). Nesse sentido, é fácil notar que os modelos de identificação das madrastas são baseados em dois opostos: a figura idealizada da mãe perfeita e as madrastas malvadas descritas na literatura infantil.

Frente a esta dicotomia, é comum as madrastas sofrerem pressões para se adaptarem ao modelo de "uma mãe como outra qualquer" apoiado e alimentado pelo mito da mãe perfeita (Smith, 1995). Não é raro, deste modo, que elas sejam induzidas a tentar, de todas as formas, "substituir" a mãe biológica a fim de que possam suprir as carências dos enteados/as. Contudo, na impossibilidade de executarem a tarefa de serem uma réplica perfeita da figura materna, são bastante freqüentes as frustrações e o aparecimento de sintomas semelhantes aos da depressão. No momento em que a madrasta se dá conta da impossibilidade de ser como a mãe, normalmente quando se defronta com algum enteado dizendo "você não é minha mãe de verdade", surge a crise (Smith, 1995). Tanto ela como o(a) enteado(a) se vêem diante da insegurança de um relacionamento cheio de riscos, de rejeição e incertezas.

O relacionamento entre madrastas e enteados/as, assim, está claramente envolto em uma dinâmica complexa, que reúne diversos fatores referentes tanto à criança, como à madrasta ou à própria relação e contexto familiar (Wagner, Sarriera, Falcke \& Silva, 1997). Entre outros, Smith (1995) e Teyber (1995) salientam que a idade e maturidade da criança, as vivências nos relacionamentos da primeira família, o momento que essa se desfez, bem como o fato dos enteados morarem 
junto com a madrasta ou conviverem apenas nas situações de visita são aspectos relevantes. Já no que se refere à madrasta, é importante observar a fase do ciclo evolutivo vital que ela atingiu em seu próprio desenvolvimento de vida e suas qualidades pessoais (interesses, estilo e personalidade).

Além disso, a dinâmica do relacionamento com os enteados reflete uma situação muito complexa. Smith (1995) salienta que o conflito entre o ideal de mãe e a imagem da madrasta malvada que circunda o imaginário social pode impulsionar a madrasta a sentir-se pressionada em amar instantaneamente seus enteados(as). Quando estas expectativas irrealistas não se cumprem, a madrasta sente-se culpada e inadequada, temendo que venha a se tornar aquela personagem cruel descrita na literatura infantil.

A experiência e a realidade têm demonstrado que, na maioria das vezes, ser padrasto ou madrasta não é o mesmo que ser pai ou mãe. Pode-se observar que os filhos nas famílias reconstituídas não têm os mesmos sentimentos por essas figuras substitutas (Wagner et al., 1997), assim como, o padrasto e a madrasta não possuem, pelos enteados, os mesmos sentimentos que possuem em relação aos seus próprios filhos. Entretanto, essa idéia não parece estar de acordo com as expectativas sociais sobre a experiência de ser madrasta ou padrasto. O que acontece então é que esta contradição se expressa através de numerosos mitos relacionados às famílias reconstituídas. Entre eles, o amor instantâneo entre madrastas e enteados, bem como as idéias de que o modelo de funcionamento das famílias reconstituídas seja idêntico ao das famílias originais e de que a madrasta necessariamente será malvada ou reparadora da ausência materna são alguns mitos que ilustram a complexidade destas relações.

Estes mitos sociais são entendidos aqui como um segredo, uma crença inconsciente ou uma atitude que, devido a uma ampla aceitação pelas gerações sucessivas de uma família ou grupo social, perpetuam-se na determinação de suas condutas (Pincus \& Dare, 1981). Os mitos crescem e se desenvolvem especificamente sobre os vazios, a falta ou escassez de dados e explicações plausíveis (Andolfi \& Angelo, 1989). Estes vazios de informações são preenchidos pela formação 
de estereótipos que induzem os participantes a determinados comportamentos. Desse modo, o mito descreve os papéis e os atributos reconhecidos, possuindo um consenso entre os membros do grupo, inclusive do portador do papel ou do status considerado (Miermont, 1994).

Desde criança, o ser humano recebe muitas informações sobre como são definidas questões importantes da sociedade e os papéis específicos quanto ao gênero, funções parentais, designações profissionais etc. A partir daí, formam-se os modelos internos de funcionamento que serão a base para o desenvolvimento do seu autoconceito (Harter, 1996).

A partir destas premissas, Fine, Kurdek e Hennigen (1992) investigaram a correlação entre os mitos sociais relativos às figuras de madrasta e padrasto e a percepção destes quanto à sua competência para o desempenho de seus papéis nas famílias reconstituídas. Os resultados encontrados indicam que a adesão aos mitos relativos às famílias reconstituídas correlaciona-se positivamente com a percepção de auto-competência dos padrastos e das madrastas. Neste caso, maiores níveis de adesão aos mitos sociais associavam-se à melhor nível de bem-estar, devido ao fato de que os padrastos e madrastas sentiam-se correspondendo às expectativas de seu contexto, no desempenho de seus papéis.

Supondo, então, que os mitos se relacionam com a percepção de auto-competência dos padrastos e madrastas, este trabalho tem por objetivo investigar como se relacionam os mitos sociais referentes aos papéis de mãe e madrasta e o nível de autoconceito (depressão, insegurança, autoconceito social, autoconceito geral, auto-estima e auto-eficácia) das mulheres que desempenham esses papéis.

\section{Método}

\section{Participantes}

Participaram desta pesquisa 50 mães e 50 madrastas, de nível sócio econômico médio, residentes na cidade de Porto Alegre. A idade média das mães foi de 43,3 anos e das madrastas 42,3 anos. A maioria 
das mães possuía o ensino médio completo (46\%) enquanto as madrastas cursavam ou já tinham concluído a graduação (48\%). Com relação à vida profissional, 34\% das mães eram donas de casa, No caso das madrastas, esse percentual era de $12 \%$. As demais mulheres tinham uma profissão e trabalhavam fora. $\mathrm{O}$ número médio de filhos era de 2,26, enquanto as madrastas possuíam em media, 1,88 enteados. Das madrastas, $40 \%$ moravam com seus enteados e $60 \%$ conviviam somente em tempo parcial. Neste último caso, a maioria (58\%) tinha contato com os enteados ao menos uma vez por semana, em média durante 9 horas. Quanto ao estado civil do cônjuge das madrastas, $84 \%$ eram separados/divorciados e $16 \%$ viúvos. A maioria das madrastas $(80 \%)$ tinha filhos biológicos.

O critério de seleção dos sujeitos foi de conveniência, por indicação de conhecidos, seguindo-se as seguintes exigências.

Madrastas: Mulheres que convivem em tempo integral ou parcial com os filhos do companheiro, no tempo mínimo de seis meses.

Mães: Mulheres casadas, em primeira união conjugal, que possuem filhos/as biológicos/as e que participam ativamente da criação e educação dos mesmos.

\section{Instrumento}

O instrumento utilizado nesse estudo consta de três partes:

(1) Dados biodemográficos

(2) Escala de Mitos (Falcke, 1998). Trata-se de uma escala composta por dez itens na qual o sujeito deveria pontuar em uma escala Likert de cinco pontos o grau de concordância que tinha com as sentenças apresentadas. As sentenças se referiam a conteúdos que eram considerados, na literatura, como mitos relacionados à maternidade ou ao papel de madrasta. Ex.: "A mãe é responsável pelo bem-estar físico e emocional dos filhos"; "Uma madrasta ama seus enteados da mesma forma que uma mãe ama seus filhos".

(3) Escala de Autoconceito de Butler e Haigh, seguindo as dimensões propostas por Sarriera (1991), que são: depressão, insegurança, autoconceito social, autoconceito geral, auto-estima e auto-eficácia. Essa escala é composta por 68 frases na qual o sujeito deve pontuar o 
seu grau de identificação com o conteúdo da sentença. Ex.: "Sempre me assusta fracassar no que vou fazer"; "Aceito a maioria dos valores e normas sociais"; "A maior parte das pessoas que me conhecem, me querem bem".

\section{Resultados e Discussão}

Os mitos de mães e madrastas: análise descritiva e comparativa

Analisou-se o grau de concordância de mães e madrastas, a partir de estatística descritiva, sobre os dez mitos apresentados na escala. Fez-se também o teste de associação qui-quadrado a fim de verificar a existência ou não de diferenças entre os dois grupos. Um resumo dos resultados obtidos em geral é apresentado na Tabela 1.

Estes resultados serão apresentados separadamente, verificando-se como as respostas referentes a cada mito avaliado na escala foram distribuídas.

(a) "Uma família reconstituída (formada de um segundo casamento) pode funcionar como uma família original (pai, mãe e filhos de uma mesma união)

É curioso verificar que a maioria das mães e madrastas $(44 \%)$ confirma tal mito, sem haver diferenças significativas na opinião delas. A idéia geradora de tal mito desconsidera as lealdades existentes entre filhos e pais biológicos criando a expectativa de que a madrasta se insira no núcleo familiar e desempenhe os papéis tradicionalmente delegados à figura feminina, assumindo as funções maternas.

(b) $\mathrm{O}$ fato de ser madrasta não compromete a mulher com a educação das crianças

Verifica-se que, igualmente, mães e madrastas, em sua maioria (59\%), optam por discordar da sentença. Este resultado corrobora a idéia de que o papel de cuidadora nas famílias se relaciona diretamente à mulher, independente da função que ela desempenha, ou seja, tanto sendo mãe como madrasta.

(c) Uma madrasta deve compensar os enteados por todas as perdas que já sofreram com a morte da mãe ou divórcio dos pais. 
Tabela 1

Adesão aos Mitos Sociais - Mães e Madrastas (Freqüências e Qui-quadrado)

\begin{tabular}{|c|c|c|c|c|c|c|c|c|c|c|c|c|}
\hline \multirow{2}{*}{ MITOS } & \multicolumn{2}{|c|}{$\begin{array}{l}\text { Concordo } \\
\text { Plenamente }\end{array}$} & \multicolumn{2}{|c|}{ Concordo } & \multicolumn{2}{|c|}{$\begin{array}{l}\text { Não concordo, } \\
\text { nem discordo }\end{array}$} & \multicolumn{2}{|c|}{ Discordo } & \multicolumn{2}{|c|}{$\begin{array}{c}\text { Discordo } \\
\text { Completamente }\end{array}$} & \multirow[t]{2}{*}{$x^{2}$} & \multirow[t]{2}{*}{$\mathrm{p}$} \\
\hline & Mãe & Madr & Mãe & Madr & Mãe & Madr & Mãe & Madr & Mãe & Madr & & \\
\hline $\begin{array}{l}\text { b. O fato de ser madrasta não compromete a } \\
\text { mulher com a educação das crianças }\end{array}$ & 1 & 2 & 15 & 13 & 7 & 3 & 21 & 23 & 6 & 9 & 2,76 & 0,59 \\
\hline $\begin{array}{l}\text { d. A mãe é a responsável pelo bem-estar } \\
\text { físico e emocional dos filhos }\end{array}$ & 18 & 14 & 25 & 23 & 3 & 4 & 3 & 8 & 1 & 1 & 2,99 & 0,55 \\
\hline e. Ser mãe faz parte da vida da mulher & 20 & 14 & 17 & 22 & 8 & 8 & 5 & 6 & 0 & 0 & 1,79 & 0,61 \\
\hline $\begin{array}{l}\text { f. Uma madrasta ama seus enteados da } \\
\text { mesma forma que uma mãe ama seus filhos }\end{array}$ & 1 & 8 & 10 & 11 & 17 & 12 & 17 & 15 & 5 & 4 & 6,59 & 0,15 \\
\hline $\begin{array}{l}\text { i. Ë difícil encontrar exemplos na vida real } \\
\text { que mostrem como é uma boa madrasta pois } \\
\text { elas costumam ser malvadas como a da } \\
\text { Branca de Neve e a da Cinderela }\end{array}$ & 0 & 0 & 7 & 8 & 11 & 5 & 27 & 23 & 5 & 14 & 6,89 & 0,07 \\
\hline j. Ser mãe é padecer no paraíso & 6 & 6 & 14 & 12 & 7 & 5 & 19 & 18 & 4 & 9 & 2,43 & 0,65 \\
\hline
\end{tabular}


Observou-se que a maioria de mães (54\%) e de madrastas (40\%) expressam algum tipo de concordância (total ou parcial) com o mito. A literatura (McGoldrick \& Carter, 1995; Smith, 1995; Teyber, 1995) salienta que são as idéias acerca do papel da mulher, como responsável pelo bem-estar emocional da família, que fazem com que muitas madrastas coloquem-se frente a uma série de expectativas, tais como essa de compensar os enteados por todas as perdas que sofreram. Isso ocorre apesar de ser evidente a impossibilidade da realização desta tarefa pelas madrastas. Provavelmente, a origem desta crença está na idéia de atribuir toda a responsabilidade à mãe pelas conquistas e fracassos dos filhos. Desta forma, nas famílias reconstituídas, continua sendo uma incumbência feminina a responsabilidade pelo cuidado das crianças só que, no caso, desempenhada pela madrasta.

(d) A mãe é responsável pelo bem-estar físico e emocional dos filhos

O fato da maioria das mães e madrastas $(80 \%)$ concordar com o mito, faz pensar na existência de uma conexão entre o ato biológico de gestar e o papel social da criação (Chodorow, 1990; Grisci, 1994). Neste sentido, supõe-se que a mulher, por ser quem gera os filhos, desenvolve um amor inato pelas crianças e fica sendo a pessoa melhor capacitada para cuidar delas.

(e) Ser mãe faz parte da vida da mulher

Um grande número de mães (74\%) e de madrastas (72\%) mostraram concordância com a frase. Esse dado aponta para a idéia de que a maternidade é parte inerente ao ciclo evolutivo vital feminino. Desde esta perspectiva, o fato de ser mãe aparece socialmente considerado como uma questão central na vida das mulheres.

(f) Uma madrasta ama seus enteados da mesma forma que uma mãe ama seus filhos

Essa foi a sentença que deixou mães e madrastas, principalmente as mães (34\%), mais em dúvida, quanto ao fato de concordarem ou não. Pode-se pensar que a exigência de que as madrastas exerçam, nas famílias reconstituídas, o papel historicamente delegado às mulheres, provoque também uma expectativa de amor equivalente entre filhos e enteados. No entanto, essa afirmação abre a possibilidade de alguém, que não a mãe biológica, possuir um tipo de amor incondicional, mito- 
logicamente atribuído, exclusivamente, à mãe. Frente a isso, mães e madrastas obtiveram um alto índice de respostas indefinidas - nem concorda, nem discorda (29\%). Ao analisar as demais alternativas dadas a essa sentença, é possível constatar que um número maior de madrastas concordam com elas ( $38 \%$ comparado a $22 \%$ de mães) enquanto a maioria das mães indica discordância total ou parcialmente (mães, 44\%; madrastas, 38\%). Apesar disso, não houve diferença significativa na opinião dos dois grupos. Provavelmente, a distribuição destas respostas pode ser explicada por duas idéias: (1) a exigência social de que madrastas sejam substitutas da mãe amando incondicionalmente seus enteados, ou ainda, sejam apenas uma mãe como outra qualquer (Bassoff, 1990; Carter, 1995; Smith, 1995); (2) a visão da mãe como uma figura insubstituível. Essas duas idéias contraditórias possivelmente explicam a ambigüidade e incerteza observadas nas respostas de mães e de madrastas.

(g) Mãe é uma só

A maioria das mulheres (66\%) acredita na veracidade da afirmação, tendo respondido que concordam plenamente ou concordam com o conteúdo da sentença. Neste caso, observa-se a preponderância da idéia da mãe como uma figura insubstituível. Provavelmente, este juízo presente no imaginário coletivo se fundamente no que Badinter (1985) chamou de mito do amor materno. A autora afirma que, sem se dar conta de intervenientes sociais, considera-se que o fato de ser mãe, por si só, desperta na mulher uma predisposição inata para amar seu filho de forma incondicional e, acima de qualquer coisa, torna-a, desta forma, insubstituível.

(h) Uma mãe tira tudo de si para dar aos filhos

O mito do amor incondicional e insubstituível também aparece refletido na opinião das mulheres entrevistadas sobre se uma mãe tira tudo de si para dar aos filhos. Constatou-se que a grande maioria de mães ( $80 \%$ ) como também de madrastas $(60 \%)$, responderam afirmativamente. Além disso, não houve nenhuma resposta de discordância total.

(i) É difícil encontrar exemplos na vida real que mostrem como é uma boa madrasta, pois elas costumam ser malvadas como a da Branca de Neve e a da Cinderela 
Apesar de ambos os grupos, em sua maioria, discordarem desta idéia, existe uma tendência entre as madrastas a discordarem de forma mais veemente que as mães $(p=0,075)$. Provavelmente isso ocorre porque elas se consideram exemplos de boas madrastas. Entre as mães, nota-se um maior número de respostas indefinidas. Neste caso, parece que é mais difícil para mães que para madrastas aceitar a possibilidade de que outra pessoa exerça de forma satisfatória a função materna.

(j) Ser mãe é padecer no paraíso

As respostas a esta sentença mostram-se bem dispersas. É interessante constatar que $50 \%$ das participantes discordam da sentença, enquanto $38 \%$ concordam e $12 \%$ nem concordam, nem discordam.

Essas respostas sugerem que, apesar da prevalência de muitos mitos referentes ao papel materno, quanto a sua incondicional doação e amor para com os filhos, as mulheres têm questionado esta idéia. Com o maior número de mulheres que entraram no mercado de trabalho e passaram a ter outras fontes tanto de alegrias como de preocupações e sofrimentos, o binômio sofrimento-plenitude parece não estar mais associado exclusivamente à maternidade.

Fazendo-se uma análise global dos resultados de forma comparativa entre os dois grupos, verifica-se que não houve diferenças significativas entre a opinião de mães e madrastas quanto aos mitos avaliados na escala. Esse resultado sugere que as crenças relativas ao papel feminino são preponderantes à condição de ser mãe ou madrasta. Assim, confirma-se que os mitos, ao descreverem papéis e atributos, passam a criar estereótipos que são reconhecidos de forma consensual pelos membros de determinado grupo social (Miermont, 1994).

Os mitos e as madrastas: análise de variáveis específicas desse grupo

Após ter-se efetuado as comparações entre os grupos de mães e de madrastas, realizou-se uma análise considerando somente o grupo de madrastas e as variáveis que o caracterizavam. Neste caso, encontrou-se os seguintes resultados: 
(a) Madrastas com filhos biológicos x madrastas sem filhos biológicos

Comparando as crenças nos mitos entre as madrastas que eram mães e aquelas que não possuíam filhos, não foi encontrada diferença significativa na opinião destes dois grupos. $\mathrm{O}$ fato de ter ou não filhos biológicos, não se encontra associado à percepção das madrastas sobre os mitos sociais.

(b) Enteados e coabitação

Não houve diferença significativa na opinião do grupo de madrastas que moravam com os enteados comparadas às que não moravam.

Considerando os fatores "a" e "b", pode-se pensar que a adesão aos mitos é anterior ao desempenho dos papéis, em função do seu caráter transgeracional. Neste caso, os mitos regem o pensamento explicativo da vivência de determinados papéis. Muito freqüentemente, então, na crença no mito, é preponderante a relevância de algumas variáveis circunstanciais.

(c) Estado civil do cônjuge antes do recasamento

Buscando associações entre o fato das madrastas estarem casadas com homens viúvos ou separados/divorciados e a adesão que estas tinham aos mitos, constatou-se uma diferença significativa na opinião desses dois grupos sobre o mito "a madrasta ama seus enteados da mesma forma que uma mãe ama seus filhos" ( $p=0,020)$, como pode-se observar nas Figuras 1 e 2.

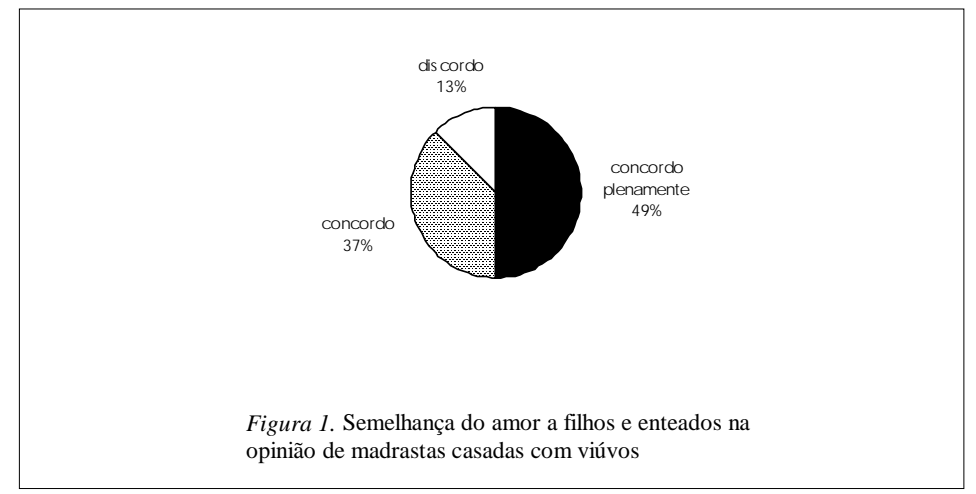




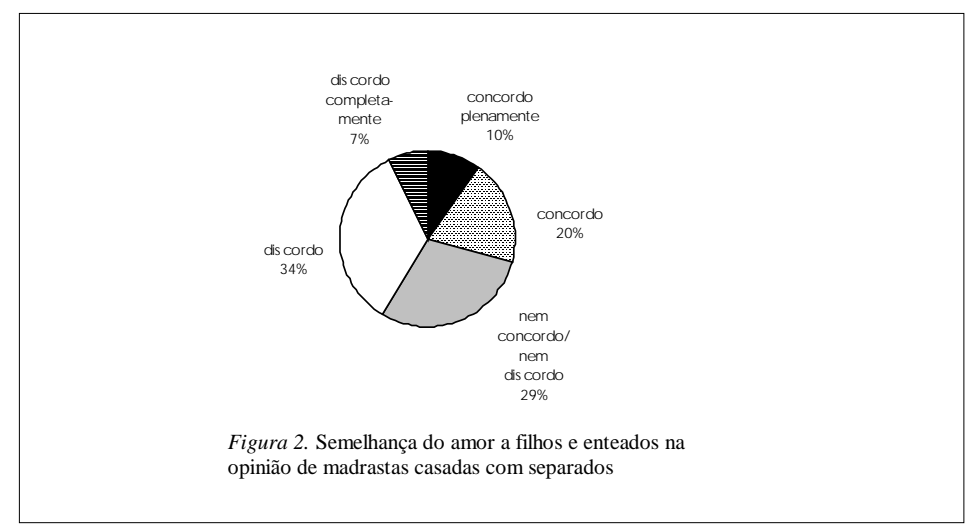

Essa diferença indica que as mulheres casadas com homens viúvos acreditam de forma mais contundente no fato de que "uma madrasta ama seus enteados da mesma forma que uma mãe ama seus filhos", comparadas às mulheres casadas com homens separados ou divorciados. É possível pensar que, na ausência da mãe biológica existe uma maior exigência e, talvez até, facilidade de substituição da função materna, pela madrasta.

Nos resultados encontrados, a partir da análise das três variáveis apresentadas - filhos biológicos, coabitação e estado civil do cônjuge -, pode-se perceber o valor e o poder que o mito social tem na vida e na conduta das pessoas. Considerando-se que o mito é um sistema de crenças, de ampla aceitação (Pincus \& Dare, 1981), constata-se que, independentemente do contexto do sujeito, nesse caso, as diferentes condições consideradas nas madrastas estudadas, ele é uma idéia quase inquestionável que tende a repetir-se e perpetuar-se por várias gerações.

\section{Autoconceito: análise comparativa de mães e madrastas}

Realizou-se uma análise comparativa entre os grupos de mães e madrastas a fim de se verificar a existência ou não de diferenças nos níveis de auto-conceito. Considerando o valor total de autoconceito, categorizado em baixo, médio e alto, bem como as dimensões estuda- 
das por Sarriera (1991), não se observou diferença entre os grupos. Pelo contrário, verificou-se que o escore total obtido por mães e por madrastas é muito semelhante $(p=0,935)$. A média de auto-conceito foi de 79,08, podendo-se considerar um nível positivo médio.

No entanto, levando-se em conta cada uma das 68 sentenças da escala, foi possível identificar itens nos quais existem diferenças, considerando-se os grupos de mães e de madrastas.

As madrastas afirmam que se identificam mais do que as mães com o conteúdo da frase "Comumente me agrada as pessoas" ( $p=$ $0,014)$. Isto pode estar relacionado ao fato das madrastas demonstrarem uma maior predisposição ao estabelecimento de relacionamentos familiares com maior flexibilidade, abertura e tolerância, pois quando uma madrasta se insere em um núcleo reconstituído, ela precisa lidar com uma série de novas relações, não somente com seu novo companheiro, mas também com enteados, toda a família extensa e, até mesmo, com a ex-esposa do companheiro ou também seu ex-esposo (Carter, 1995). Sendo assim, pode-se pensar que as madrastas demonstram ter um menor nível de exigência no relacionamento com as demais pessoas comparado ao grupo de mães e, por isso, sentem que as pessoas comumente lhe agradam.

Por outro lado, uma outra sentença que indica diferença significativa entre os dois grupos é a que se refere ao sentimento de desespero. As madrastas se percebem mais desesperadas do que as mães ( $p=0,021$ ). Além disso, associado a esse fato, elas também consideram, em maior proporção que as mães, que têm fracassado totalmente ( $p=0,001)$ e têm uma forte tendência a verem suas vidas mais confusas $(p=0,056)$.

Pode-se pensar que a complexidade nos relacionamentos existentes nas famílias reconstituídas e a dificuldade na definição de um papel específico a ser desempenhado pelas madrastas são fatores que podem estar contribuindo para esse sentimento de confusão. Além disso, a literatura salienta a existência de sentimentos de fracasso, quando descreve vários pontos do entendimento da vivência interna de uma madrasta. McGoldrick (1995) comenta que é comum as madrastas sentirem como um fracasso seu a incapacidade de formar uma 
família feliz, pela tendência das mulheres em assumir a responsabilidade de êxito ou fracasso nos relacionamentos familiares. Por sua vez, Smith (1995) lembra que é difícil para as madrastas aceitarem que não poderão ser, para os enteados, como sua própria mãe e, frente a essa constatação, é comum terem sentimentos de inadequação, ansiedade, culpa, entre outros. Provavelmente, esses fatores exerçam influência na visão das madrastas sobre suas vidas e elas tenham esses sentimentos de fracasso, confusão e desesperança.

As madrastas também mostraram uma maior identificação com o conteúdo da sentença "Me vejo obrigada, muitas vezes, a desculparme" $(p=0,055)$. É fácil pensar que falte às madrastas o conhecimento íntimo com relação aos enteados e, muitas vezes, haja conflito entre as suas necessidades, as deles e as expectativas sociais com relação ao papel que cada um deve representar na relação (Smith, 1995). Estas dificuldades podem conduzir a situações conflitivas nas quais é necessário o pedido de desculpas.

Estas foram as frases com as quais as madrastas demonstraram possuir maior identificação com significativa diferença na comparação com o grupo de mães. Na continuação, serão discutidos os dados referentes às frases em que as mães consideraram que descrevem melhor seus sentimentos e vivências.

As mães apontam, com significativa diferença, comparadas às madrastas $(p=0,026)$, que se identificam com maior intensidade com o conteúdo da frase "Minhas batalhas mais duras são comigo mesma". Nesse sentido, percebe-se que as mães demonstram ter maiores conflitos internos do que externos. Provavelmente, os mitos sociais tenham uma grande influência neste sentimento das mães na medida em que a mulher-mãe fica aprisionada nos estereótipos designados ao papel que desempenha. Além disso, historicamente as designações femininas vêm carregadas de muitas exigências e, comumente, tiram das mulheres o direito de participarem das tarefas socialmente mais aceitas, por vangloriar preponderantemente suas funções reprodutivas (Grisci, 1994).

As mães também afirmam que sentem-se significativamente mais escravizadas na comparação com as madrastas $(p=0,03)$ o que pode 
explicar-se pelo fato de que as mães que participaram deste estudo têm menor escolaridade que as madrastas e realizam mais atividades de donas de casa. Neste caso, o trabalho doméstico de cuidado com os filhos, com o marido e a casa (Ariès, 1981) em detrimento de uma vida profissional, podem reforçar a sensação de estar escravizada.

As mães, com diferença significativa em relação às madrastas, ainda apontam que tratam de não pensar nos seus problemas ( $p=$ $0,011)$ e não confiam nas suas emoções $(p=0,009)$. Elas também têm uma tendência a se policiarem mais nas coisas que fazem $(p=0,058)$.

Observa-se que estas três sentenças apontam uma problemática preponderantemente relacionada a conflitos internos, relacionados a dificuldades de resolver problemas, insegurança e censura. Sabe-se que da figura materna é esperado que tenha somente sentimentos de generosidade, bondade, tolerância e doçura (Serrurier, 1993) e, conseqüentemente, devem ser negados sentimentos hostis como raiva e frustração. Provavelmente, a forma de lidar com tais emoções é negando-os ou policiando o que fazem.

Por outro lado, com relação à sentença "Sou uma pessoa equilibrada", as mães se identificam significativamente mais com esse conteúdo do que as madrastas ( $p=0,023)$. Possivelmente, a idéia de equilíbrio, embora em algumas ocasiões aparente, também esteja associada à um maior grau de aceitação social. Desta forma, é coerente e útil que as mães mantenham seus conflitos ocultos internamente.

Na comparação de características específicas do grupo de madrastas com as dimensões do autoconceito, não se observou diferença significativa entre as que moram com os enteados e as que não moram, ou seja, entre as madrastas de tempo total e parcial. Esse fato não se relaciona ao autoconceito das madrastas, provavelmente porque, como relata a literatura, tanto as madrastas de tempo integral como parcial lutam com os mesmos problemas (Smith, 1995). Por outro lado, Lambert (citado por McGoldrick \& Carter, 1995) considerou a possibilidade de existir uma maior ambigüidade no papel desempenhado por madrastas de tempo parcial, já que, nessas condições, a madrasta pode sentir-se menos ligada às crianças, perturbada e explorada durante as visitas e tem que aceitar a presença maior da mãe 
biológica na vida dos enteados. Além disso, Smith (1995) salienta que, mesmo sendo madrasta em tempo parcial, existe uma expectativa pública de que seja maternal, ainda que não tenha os direitos de mãe. Apesar dessas constatações, neste estudo, viu-se que esses aspectos não se refletiram nas dimensões de autoconceito das madrastas em tempo total ou parcial.

Contrariando o que diz a literatura a respeito de que a vivência do papel de madrasta é mais fácil quando ela também possui filhos, e assim, ambos os cônjuges experienciam os papéis de padrasto e madrasta (Smith, 1995), verificou-se neste estudo uma tendência ( $p=$ $0,07)$ de que as madrastas que possuíam filhos biológicos se mostrassem mais deprimidas. Esses dados podem estar indicando, entre outras variáveis, a complexidade de reunir a demanda de dois conjuntos de crianças - filhos e enteados - em posições diferenciadas, porém, muitas vezes, com exigências semelhantes. A partir dos dados na escala de mitos em que a maioria, tanto de mães como de madrastas, acredita na possibilidade de que uma madrasta ame seus enteados da mesma forma que uma mãe ama seus filhos, deve ser um conflito importante para as madrastas que possuem filhos perceberem que é diferente o sentimento que possuem por um ou outro grupo.

Como último fator de análise entre características do grupo de madrastas e as dimensões do autoconceito, verificou-se que é significativamente maior o nível de auto-conceito social de madrastas com companheiros viúvos que com companheiros separados/divorciados $(p=0,019)$.

Parece que se comprova a idéia de que a ausência física da mãe biológica facilita o desempenho do papel materno pela madrasta e, consequentemente, haja um maior nível de aceitação social. Outro aspecto facilitador deste processo é o fato de ser esperado socialmente que, após a morte da esposa, o viúvo volte a casar-se para que outra mulher possa ajudá-lo a tomar conta das crianças. É comum um reconhecimento social pela madrasta que assume a maternagem das crianças que sofreram com a perda da mãe.

Do contrário, as madrastas cujos companheiros são separados precisam lidar com a presença da mãe e ex-mulher, o que pode ocasio- 
nar uma maior indefinição do seu lugar, principalmente na vida dos enteados. Além disso, muitas vezes, existe a idéia de que ela foi a causadora da separação. Desde esta perspectiva, socialmente, seu papel é mais contestado e conflituoso.

\section{Escala de mitos versus escala de auto-conceito}

Ao estabelecer-se a comparação entre as escalas de mitos sociais e autoconceito, verificou-se a inexistência, em todos os itens, de associação entre os níveis de autoconceito (baixo, médio e alto) e a opinião de mães e madrastas quanto aos mitos sociais. Nesse sentido, a análise indica que o índice de autoconceito obtido independente do grau de adesão aos mitos sociais. Pode-se pensar que, por se tratar de uma escala de medida do autoconceito geral, os mitos sociais relacionados aos papéis específicos de mães e de madrastas demonstraram não estarem presentes de forma significativa nessa medida. Provavelmente, poderiam existir diferenças se fosse avaliado o autoconceito específico no desempenho das funções e do papel de mãe e madrasta no núcleo familiar.

\section{Conclusões}

Refletindo sobre os resultados encontrados nessa pesquisa, é possível visualizar a complexidade da vivência feminina implicada no desempenho tanto do papel de mãe como no de madrasta. Em vista de todos os itens da escala de mitos sociais analisados e da ausência de diferenças significativas entre a opinião de mães e madrastas, o fato que surge como constatação mais provável é que as sentenças analisadas parecem refletir crenças que realmente pertençam ao imaginário popular, perpassando a experiência das mulheres de forma quase inquestionável, independentemente de sua condição como mãe ou madrasta.

Dentre os mitos analisados, destaca-se a concepção da mulher como cuidadora e responsável pela felicidade e bem-estar da família. Neste estudo, pôde-se demonstrar que as mulheres ainda trazem um forte legado transgeracional relacionado ao estereótipo de gênero, ainda que muitas mudanças sociais venham ocorrendo nesses últi- 
mos tempos. Neste caso, pode-se perceber a força e o poder do mito como uma idéia muito presente, à qual as mulheres respondem de forma quase automática.

Em uma análise macrossistêmica, ficam claras as transformações da posição da mulher no contexto social, que cada vez mais vem ocupando seu espaço no mercado de trabalho e ampliando sua representatividade na sociedade. No âmbito familiar, pode-se verificar, através de pesquisas ("Família", 1998), que a mulher vem abarcando maiores responsabilidades e agora integra tanto as funções de cuidado, nutrição, afeto entre outras que já lhe cabiam, como também, o papel principal de disciplinadora, além de ser uma participante ativa na divisão das despesas domésticas. Apesar deste novo contexto, o mito social relativo ao papel feminino demonstra-se preponderante.

Outro aspecto que corrobora a força do mito encontra-se presente no papel da madrasta nas famílias reconstituídas. Os mitos associados à figura da madrasta, provavelmente, são alguns dos fatores dificultadores da construção de relações mais saudáveis e produtivas nestes núcleos familiares, pelo fato de haver uma predisposição à repetição do papel materno, entre outras expectativas.

A expressão da conflitiva provocada, entre outras coisas, pela adesão inquestionável aos mitos sociais pode estar explicando, de alguma forma, a necessidade de manter-se uma estrutura familiar milenarmente definida pelo amor exclusivo, incondicional, insubstituível e natural à mãe biológica. Desde esta perspectiva, podese avaliar, com maior propriedade, a necessidade de revisar os papéis que tradicionalmente as mulheres vêm assumindo na família assim como redefinir o funcionamento familiar frente a um novo contexto social. De outra forma, estaremos condenados a repetir indefinidamente padrões de interação empobrecedores de relações familiares que poderiam ser mais criativas e saudáveis.

\section{Referências}

Andolfi, M., \& Angelo, C. (1989). Tempo e mito em terapia familiar. Porto Alegre: Artes Médicas.

Ariès, P. (1981). História social da criança e da família. Rio de Janeiro: LTC. 
Badinter, E. (1985). Um amor conquistado: o mito do amor materno. Rio de Janeiro: Nova Fronteira.

Bassoff, E. (1990). Mães e filhas: a arte de crescer e aprender a ser mulher. São Paulo: Saraiva.

Carter, E. (1995). Famílias reconstituídas: a criação de um novo paradigma. In M. Andolfi, C. Angelo \& C. Saccu (Orgs.), O casal em crise (pp. 193-198). São Paulo: Summus.

Chodorow, N.(1990). Psicanálise da maternidade: uma crítica a Freud a partir da mulher. Rio de Janeiro: Rosa dos Tempos.

Família. (1998, 20 de Setembro). Folha de São Paulo, p. A-1.

Falcke, D. (1998). Mães e madrastas: mitos sociais e autoconceito. Dissertação de mestrado não-publicada, Pontifícia Universidade Católica do Rio Grande do Sul, Porto Alegre, RS.

Fine, M. A., Kurdek, L., \& Hennigen, L. (1992). Perceived self-competence, stepfamily myths and (step)parent role ambiguity in adolescents from stepfather and stepmother families. Journal of Family Psychology, 6 (1), 69-76.

Grisci, C. L. I. (1994). Mulher-mãe: a ideologia patriarcal na reprodução das relações de gênero. Dissertação de mestrado não-publicada, Pontifícia Universidade Católica do Rio Grande do Sul, Porto Alegre, RS.

Harter, S. (1996). Historical roots of contemporary issues involving self-concept. In B. A. Bracken (Org.), Handbook of self-concept: developmental, social and clinical considerations (pp. 1-37). New York: John Wiley.

McGoldrick, M. (1995). As mulheres e o ciclo de vida familiar. In B. Carter \& M. McGoldrick (Orgs.), As mudanças do ciclo de vida familiar: uma estrutura para a terapia de família (pp. 30-64).Porto Alegre: Artes Médicas.

McGoldrick, M., \& Carter, B. (1995). Construindo uma família recasada. In B. Carter \& M. McGoldrick (Orgs.), As mudanças do ciclo de vida familiar: uma estrutura para a terapia de família (pp. 344-369). Porto Alegre: Artes Médicas.

Miermont, J. (1994) Dicionário de terapias familiares: teoria e prática. Porto Alegre: Artes Médicas.

Pincus, L., \& Dare, C. (1981). Psicodinâmica da família. Porto Alegre: Artes Médicas.

Sarriera, J. C. (1991). Identificación de escalas en el Test de Autoconcepto de Butler y Haigh. Manuscrito não-publicado.

Serrurier, C. (1993). Elogio às mães más. São Paulo: Summus.

Smith, D. (1995). Madrastas: mito e realidade. como desempenhar este difícil papel. Porto Alegre: L\&PM.

Teyber, E. (1995). Ajudando as crianças a conviver com o divórcio. São Paulo: Nobel.

Wagner, A., Sarriera, J. C., Falcke, D., \& Silva, C. B. (1997). Adolescentes y familias: un estudio comparativo entre familias de origem y reconstituidas. Cuadernos de Terapia Familiar, 2 (35/36), 119-127. 
Denise Falcke, piscóloga, é mestre em Psicologia Clínica e doutoranda do Programa de Pós-Graduação em Psicologia da Pontifícia Universidade Católica do Rio Grande do Sul. Bolsista CAPES.

Adriana Wagner, doutora em Psicologia, é professora do Programa de Pós-Graduação em Psicologia da Pontifícia Universidade Católica do Rio Grande do Sul.

Endereço para correspondência: Trav. Olimpio de Oliveira Pacheco, 18/301, Bairro Jardim Itati, 91370070, Porto Alegre, RS.

E-mail:

D.F.: dfalcke@yahoo.com;

A.W.: wagner@pucrs.br 